\title{
LA INFLUENCIA DE LA MEDICINA ÁRABE EN LA INTERPRETACIÓN DE AVERROES AL DE ANIMA DE ARISTÓTELES
}

\author{
Luis Xavier López Farjeat
}

\begin{abstract}
RESUMO - Neste trabalho apresento algumas contribuições de Averróis a respeito de problemas relativos à psicologia e à medicina. Minha intenção é estabelecer algumas relações entre os comentários ao De anima e os tratados de medicina. O itinerário é o seguinte: a) Mostrarei gue, tal como Aristóteles, Averróis concebe a alma como um conjunto de capacidades biológicas; b) De anima é um tratado de biologia e, por isso, podemos encontrar nele algumas considerações que devem ser entendidas a partir de um ponto de vista médico, especialmente a partir da contribuição árabe para a anatomia. É necessário, pois, acentuar a importância dos nervos e do cérebro para compreender a estreita relação entre o De anima e o Livro da Medicina. Haveremos de constatar que Averróis não compreende a alma como um 'princípio espiritual', como semelhante a algo gerado, que torna possível diversas funções biológicas, desde a vegetativa e a sensitiva, até a intelectual. Assim, Averróis nega a concepção neoplatônica da alma como algo separado do corpo. Averróis explica que a alma é e concretização do processo biológico chamado 'vida'.

PALAVRAS-CHAVE - Averróis. Aristóteles. De anima. Neoplatonismo. Biologia. Vida.
\end{abstract}

ABSTRACT - In this paper I will show some contributions from Averroes around some issues related to psychology and medicine. My intention is to establish some relations between the commentaries on De anima and the medical treatises. The itinerary is the following: a) I will show that, like Aristotle, Averroes conceives the soul as a set of biological capacities; b) De anima is a biological treatise, so there we can find some considerations that must be understood from a medical point of view, specially, from the Arabic contributions on Anatomy. It is necessary, then, to point out the importance of the nerves and the brain to understand the narrow relation between the De anima and the Book of Medicine. We will find that Averroes does not understand the soul as a 'spiritual principle' but like something generated that makes possible several biological functions, from the vegetative and the sensitive to the intellectual ones. So, Averroes denies the Neoplatonic conception of the soul as something separated from the body. Averroes explains that the soul is the concretion of the biological process denominated "life".

KEY WORDS - Averroes. Aristotle. De anima. Neoplatonism. Biology. Life.

Esta investigación forma parte del proyecto de investigación titulado "La filosofía de la mente en el aristotelismo árabe y latino" (CONACYT 49596)

Universidad Panamericana, México.llopez@mx.up.mx

\begin{tabular}{|l|l|l|l|l|l|}
\hline VERITAS & Porto Alegre & v. 52 & n. 3 & Setembro 2007 & p. 91-103 \\
\hline
\end{tabular}




\section{Resumen}

Mi objetivo es mostrar que, desde cierto punto de vista, la interpretación averroísta del De anima permite una lectura naturalista o, si se quiere, fisicalista. ${ }^{1}$ El itinerario es el siguiente: a) mostraré que la noción averroísta de la psychē como un conjunto de capacidades biológicas, es fiel a la concepción aristotélica que encontramos en De anima y, también, en algunos pasajes de la Reproducción de los animales; ${ }^{2}$ b) puesto que De anima es un tratado biológico, no puede leerse al margen de la ciencia médica averroísta y, específicamente, de la anatomía. Haré algunos señalamientos sobre la función de los nervios y del cerebro. Hay, pues, una estrecha relación entre (a) y (b). En (a) mostraré que Averroes no entiende el alma como un 'principio espiritual' sino como algo generado que posibilita varias operaciones, desde las vegetativas y sensitivas hasta las intelectuales. Los incisos (a) y (b) servirán para confirmar que (i) el alma es principio de operaciones biológicas; (ii) que, como tal, no es una forma separada que desciende a un cuerpo como pensaron los neoplatónicos -, sino que es, más bien, la concreción del proceso biológico denominado 'vida'. Una vez que Averroes ha desarrollado sus comentarios a los pasajes dedicados a los sentidos externos y a los sentidos internos, pasa a uno de los temas más complejos de la historia de la filosofía: el noūs. Me detendré solamente en la noción averroísta del noūs pathetikós, generable y corruptible. Los problemas que van más allá de este noūs pathetikós sobrepasan las intenciones de mi trabajo.

En De anima 403 b 17, Aristóteles afirma que "las afecciones del alma no son separables de la materia natural de los animales". Averroes reafirma esta posición, precisamente, en sus comentarios a ese tratado, en otros trabajos en donde toca el tema del intelecto y, además, en su obra médica. Me centraré exclusivamente en el Epítome (redactado aproximadamente entre 1158-1160) y en el Libro de las generalidades de la Medicina (Kitāb al-Kulliyyāt fīl-tibb). En ambos hay planteami-

\footnotetext{
Averroes redactó tres comentarios al tratado aristotélico que nos ocupa. Hay cambios notorios entre ellos. (Para mayor conocimiento de las diferencias entre el Epítome, el Comentario Medio y el Gran Comentario, cf. A. IvRY: "Averroes' Three Commentaries on De Anima", en Averroes and the Aristotelian Tradition, G. ENDRESS y J. A. AERTSEN (eds.), E. J. Brill, Leiden, 1999, p.199-216). En árabe se conservan solamente versiones del Epítome (Ŷămi' kitāb al-nafs) (cf. AvERROEs: Epitome De anima, edición S. GÓMEz NogALES, Consejo Superior de Investigaciones Científicas, Instituto Hispano-Árabe de Cultura, Madrid, 1985) y del Comentario Medio (Taljīs kitāb al-nafs) (cf. AverROes: Middle Commentary on Aristotle's De anima, edición crítica del texto árabe a cargo de A. L. IVRY, Brigham Young University Press, Provo, Utah, 2002.). Del Gran Comentario (Commentarium Magnum in Aristotelis De Anima) sólo se conserva la conocida versión latina traducida por Miguel Escoto (cf. AverRoes: Commentarium magnum in Aristotelis De anima libros, The Mediaeval Academy of America, Cambridge, Massachussets, 1953.). En estos trabajos Averroes se opone a las explicaciones místicas, religiosas o espirituales del alma que aparecen en sus antecesores neoplatónicos, especialmente al-Fārābīi, Ibn Sīnā e Ibn Bājja. Averroes, al fin y al cabo un médico, piensa que el estudio del alma humana exige un estudio previo del género animal.

2 Los Libros de los animales (Kitāb al-hayāwān) fue el título con el que los árabes integraron los diecinueve libros que integran todos los escritos aristotélicos sobre los animales. Cf. MicHAEL SCOT: Aristotle De Animalibus, E. J. Brill, Leiden, 1992.
} 
entos muy similares. He elegido el Kitāb al-Kulliyyāt por lo que ahí se afirma sobre la generación de la vida y sobre los nervios y el cérebro. ${ }^{3}$

\section{Aristóteles y Averroes: la noción de psychē}

Los términos psychē y zōē se relacionan estrechamente en la filosofía aristotélica. Con el término psychē Aristóteles no da entender solamente los actos mentales sino que, precisamente, psychē refiere los actos de los seres vivos incluyendo procesos biológicos no conscientes, como la nutrición y el crecimiento. Averroes sigue la misma dirección que Aristóteles: se inscribe en una psicología naturalista. Veremos más adelante que concluye, como Aristóteles, dándose cuenta que el noūs no se explica tan fácilmente como una operación biológica. En Partes de los animales 641 a 18-23, Aristóteles afirma que al salir del alma, el viviente deja de vivir y concluye que por eso a físicos y biólogos corresponde el estudio del alma en tanto que ésta es principio de funciones vitales u orgánicas. Aunque el alma puede tener funciones más elevadas como la intelección, sus funciones son en buena parte biológicas. La biología aristotélica descarta que el alma y el cuerpo existan por separado: o el alma es ousía en tanto que eīdos de un cuerpo natural (412 a 19-21); o es entelékheia de un cuerpo natural orgánico que posee vida en potencia (412 a $27-28)$.

La relación entre alma y cuerpo es tan estrecha para Aristóteles, que en De anima 414 a 19-20 afirma que "el alma ni es cuerpo, ni existe sin el cuerpo". Este breve pasaje ha dado mucho de qué hablar: por una parte, el alma no es cuerpo, con lo cual parecería que Aristóteles no es un biologista radical. Paradójicamente, no puede darse un alma sin el cuerpo. Ello nos permite pensar que no estamos hablando de dos elementos que coexisten armónicamente, sino de dos elementos que son distintos y se integran y, dado que uno es entelékheia del otro, parece que a fin de cuentas hay cierta prioridad del alma. Ahora bien, ésta no es en el caso de Aristóteles un principio espiritual preexistente que se inserta súbitamente en un cuerpo. Lo que me parece muy sugerente es que posiblemente para Aristóteles el alma se identifica con el desarrollo biológico. Psychē y zōe están tan relacionadas que el desarrollo del ser viviente se da simultáneamente con el desarrollo progresivo de determinadas funciones biológicas: desde algunas elementales como la nutrición y el crecimiento hasta otras más complejas como la sensación. Así se describe en De anima 412 a 11-15 y en 413 a 20. Hay un pasaje más, 414 a 1213, en donde se lee: "El alma es aquello por lo que primariamente vivimos, sentimos y pensamos". Pero entonces, ¿el alma se genera al mismo tiempo que se genera el primer indicio de un cuerpo dispuesto a ser viviente? Es decir, ¿el desarrollo progresivo del alma es paralelo al desarrollo de lo que llamaríamos embrión?

Se discute mucho la fecha de composición de este libro. M. Alonso sostiene que se escribió entre 1162 y 1169 (cf. M. ALONSO: Teología de Averroes. Estudios y documentos, CSIC, Madrid/Granada, 1947, p. 69). Sin embargo, el trabajo podría ser anterior, aproximadamente de 1146-1148. 
Pasemos ahora a Averroes. En Kitāb al-Kulliyyāt, ${ }^{4}$ Averroes recurre a varios médicos y filósofos, especialmente, a Hipócrates, a Galeno, Avicena y, por supuesto, a Aristóteles. Comento un pasaje muy concreto de Averroes, aquél en donde explica la utilidad de los órganos reproductivos y, por lo tanto, cómo es que se genera la vida $(z \bar{o} \bar{e})$. Averroes piensa que en el acto reproductivo el esperma aporta la forma, tal como lo sostuvo Aristóteles. El esperma es un líquido residual que, al mezclarse con el 'esperma femenino' y con la sangre, permite que se forme un cuerpo (materia) que se nutre paulatinamente. ${ }^{5}$ El esperma tiene un papel esencial en la reproducción. ${ }^{6}$ Pero tampoco puede él por sí mismo generar vida, puesto que requiere interactuar con otros fluidos y, además, como veremos a continuación, con el calor innato. ${ }^{7}$ De ese modo se conforma un embrión que en el cuerpo femenino manifestará dos funciones propias del alma vegetativa: nutrición y crecimiento. Escribe Averroes:

Entre las señales que yo considero de que el esperma masculino ocupa el lugar de sujeto agente está que los órganos solamente se alimentan mediante el calor innato del corazón, y siendo este calor el instrumento primero de la facultad nutritiva, es necesario que la potencia nutritiva sea el primer instrumento de la facultad generativa. De aquí se deduce que en el esperma del hombre o en la sangre del útero existe, necesariamente, gran parte de este calor innato. Pero éste no puede existir más que en el esperma, debido al calor y a la humedad que hay en él. En cuanto a la sangre de la que procede el feto es una sangre venosa, que está muy lejos de poseer tal calor, pues es sangre sin digerir y todavía más remota es [la posibilidad de que] se encuentre en el esperma femenino. Tampoco se puede decir que el calor innato se origine en el feto de por sí, ya que el calor innato no lo

${ }^{4}$ Utilizaré el Libro de las generalidades de la Medicina (Kitāb al-Kulliyyāt fīl-tibb) traducido por María de la Concepción Vázquez de Benito y Camilo Álvarez Morales, Trotta, Madrid, 2003.

5 "Siendo notorio esto y siendo cierto que no es posible que el esperma femenino y el masculino realicen una acción de la misma especie, y siendo, asimismo, evidente que la mujer tiene influencia en la generación, es menester que su papel sea distinto al del hombre y que sus acciones converjan a un solo fin, que es la formación del embrión. Cada uno de ellos dará a este embrión una parte de su ser, y las partes de una cosa son dos: materia y forma. Por tanto, uno de ellos le dará la materia y el otro la forma. No podemos decir que la mujer sea la que da la forma y el hombre la materia, sino al contrario, pues el que da el alimento es el que da la materia, necesariamente. Aristóteles opina que el varón es el que da la forma y la hembra la que da la materia. Pero la hembra no tiene otra cosa que podamos considerar como materia más que su esperma o su sangre menstrual; ahora bien, el esperma es un líquido acuoso parecido a un residuo, o mejor aún, es un verdadero residuo del que no se pueden nutrir los órganos, luego la sangre basta para ello, puesto que ella sí nutre a los órganos. Y no hay diferencia entre la materia de la nutrición y la de la generación, porque la nutrición forma al embrión en parte y la generación en todo; y la materia del todo y la parte es la misma. También se demuestra que el esperma de la mujer no es material del embrión, porque muchas mujeres se han quedado embarazadas sin haber segregado esperma, como ya hemos dicho. Además, el útero arroja el esperma hacia fuera y atrae el esperma masculino hacia dentro, todo lo cual es indicio de que el esperma femenino es un líquido residual que fluye cuando se experimenta placer sexual, del mismo modo que fluye la saliva de la boca del hambriento cuando ve la comida" (AvERROES: Kulliyyāt, 28). Un pasaje muy similar al que cito, puede encontrarse en 726 a 30-35; también en 727 a 25-728 b 30.

6 Para la descripción y función del esperma, cf. ARISTÓteles: Reproducción de los animales 724 a 15726 a 25. Para su naturaleza, cf. 735 a $30-736$ a 20.

Cf. ARISTÓteles: Reproducción de los animales 736 a 25ss. 
engendra más que el calor natural, como el calor que posee quien lo nutre [al feto].

El desarrollo o crecimiento de un embrión supone, obviamente, un cambio o transformación de un organismo vivo. ${ }^{9}$ Tal transformación es posible gracias a la psychē. Ésta, insisto, no ha sido descrita como un principio independiente o separable del organismo. Averroes piensa, más bien, que los cambios en el nuevo organismo vivo son posibles por la intervención del calor que hay en el esperma ${ }^{10}$ que se conserva en el cuerpo femenino:

Es posible que en el útero se halle la facultad transformativa, como parece obvio, pero nosotros no podemos decir que sea el lugar en el que se forman los órganos del feto sino que solamente emplea la facultad formativa utilizando el calor que hay en el esperma. Si el útero fuera el que creara los órganos del embrión, la mujer engendraría por sí misma, pero siendo como es, su función es la de la facultad transformativa, que no tiene más fin que el de conservar, y por ello cuando el esperma se pone en contacto con el aire su constitución se corrompe. Según esto, se comprende que en el útero haya una facultad transformadora. ${ }^{11}$

Las tesis que aparecen en la cantidad de pasajes análogos que hay entre Kitāb al-Kulliyyāt y la Reproducción de los animales, saltan inmediatamente a la vista. Averroes cita estos últimos cuando nos recuerda de dónde proviene el alma:

Con todo esto se declaró en el Libro sobre los animales que son tres las clases de composición. La primera composición es la que proviene de la existencia de los cuerpos simples en la materia primera, la cual no está informada por esencia. La segunda composición es la que consta de estos simples, que son los cuerpos de partes homogéneas. La tercera composición es la propia de los miembros orgánicos, que son los de existencia más completa en el animal perfecto, como el corazón y el hígado. Y tal vez se dé también a modo de proporción y analogía en el animal que no es perfecto. También se encuentra en las plantas como es en las raíces y en las ramas. También se ha declarado en este libro que el engendrador próximo de estos cuerpos no es el calor elemental, ya que la acción del calor elemental es únicamente el endurecimiento y la sequedad y algunas otras de las cosas que se refieren a los cuerpos homogéneos. Sino que el engendrador es una facultad semejante a la potencia de la función activa, como dice Aristóteles. ${ }^{12}$

En el Epítome aparecen pasajes como éste en el que se describe la conformación del ser vivo. Se menciona la diferencia que existe entre la planta y el animal. Este último posee órganos mucho más complejos. Averroes menciona solamente

\footnotetext{
AvERROES: Kulliyyāt, 28.

Cf. ARISTÓTELES: Reproducción de los animales 733 b 25ss.

Cf. ARISTÓteles: Reproducción de los animales 736 b 30-35.

AvERROES: Kulliyyāt, 28.

AverRoES: Epítome, 5. El subrayado es mío. Utilizo el texto árabe establecido por S. GÓmEZ NoGALES, ed. cit., y su traducción publicada con el título La psicología de Averroes, Universidad Nacional de Educación a Distancia, Madrid, 1987. En algún caso, me he tomado la libertad de hacer ligerísimas modificaciones.
} 
el corazón y el hígado, pero también ha de sumarse el cerebro y todos los órganos que integran el cuerpo animal. La presencia de estos órganos que hacen posible la sensación (aísthesis) y, en cierta medida, el pensamiento, marca una diferencia esencial con las funciones propias de una planta. Con la presencia de las funciones vegetativas y con la centralidad que tiene la sensación como operación característica del animal, es más que evidente que por psychē Aristóteles y Averroes entienden el conjunto de funciones que posibilitan la vida. Aceptan, además, que la vida animal es más perfecta que la vegetativa, dado que las funciones animales son más complejas. De ahí que el cuerpo animal esté compuesto de diversas partes orgánicas dispuestas a hacer posible la sensación. ${ }^{13}$

\section{Aristóteles y Averroes: la noción de aísthesis}

Podemos encontrar en Averroes un estudio sumamente completo de la sensación (aísthēsis). Tengamos en cuenta que la medicina estaba entonces mucho más avanzada que en tiempos de Aristóteles y, por tanto, había una comprensión mucho más aguda de la corporalidad. Una de las funciones más importantes a lo largo de De anima es la sensación o aísthēsis. Leemos en 413 b 2 que lo que caracteriza primariamente a un animal vivo es la sensación. Quisiera proponer que, finalmente, la doctrina del intelecto supone todo el proceso de la sensación, al menos si queremos explicar la acción del intelecto posible de De anima III, 5. No podríamos llegar a ese punto sin la sensación. Averroes, como Aristóteles, se percata de ello y, por eso, se dedica hondamente al estudio, digamos biológico, de la sensación y el cuerpo como agente de la sensación. Averroes valora especialmente al corazón y al cerebro. Mantiene la idea aristotélica de que el corazón constituye el núcleo del calor interno de los animales y el cerebro enfría y, por tanto, atempera. ${ }^{14}$ Averroes se refiere al corazón como órgano fundamental del animal $^{15} \mathrm{y}$ al cerebro como fuente de la potencia atemperadora:

Sin embargo, si no hay más remedio que el nervio forme parte de la existencia del sentido, pues ojalá yo supiera de qué modo sea esto. Decimos, pues: cuando se observa lo que se declaró en el Libro sobre el Animal, que el sujeto primero de esta potencia y de las demás potencias restantes del sentido es el calor nutritivo, que está por sí mismo en el corazón, y en los demás miembros en cuanto están unidos a él por medio de las arterias que provienen del corazón, y que el cerebro existe únicamente con miras al equilibrio de este calor nutritivo en el órgano del sentido; y esto porque sería imposible el que esta potencia sintiese las cosas que sobrepasan el equilibrio adquiriendo cualidades desmesuradas, a no ser que su órgano esté en el máximo del término medio y del equilibrio para poder percibir todos los extremos que se salgan de él, y ésta es la condición de la carne. Y por eso, cuanto más equilibrada esté la carne, el sentido será mayor, como lo vemos en el sentido interior de la palma de la mano. En cambio, el nervio tiene una com-

\footnotetext{
Cf. AVERROES: Epítome, 30-41.

Cf. ARISTÓteles: Reproducción de los animales 743 b 25-30.

Cf. AverRoEs: Epítome, 7.
} 
plexión que está lejos de la mezcla intermedia, y por eso, es difícil su sentido por frío y seco. ${ }^{16}$

En este pasaje ya se vislumbra la ventaja que tiene Averroes sobre la teoría aristotélica de la sensación. Me refiero a la alusión a los nervios. Al elaborar su análisis del cerebro y del sistema nervioso, las fuentes de Averroes son dos, a saber, la medicina galénica y su recepción y desarrollo entre los árabes. Revisemos los pasajes en los que se establece que la sensación se explica desde los nervios y el cerebro:

En cuanto a la utilidad de este enfriamiento que realiza el cerebro en cada uno de los sentidos, ya se ha investigado sobre ello en el Libro sobre el Animal. Y si suponemos todo esto así, y añadimos a ello que los nervios únicamente provienen del cerebro, porque son semejantes en su sustancia, y se deduce del conjunto de todo ello que la carne únicamente siente con una sensación completa por medio del calor nutritivo que está en ella, cuando se equilibra su calor con los nervios que llegan a ella desde el cerebro, parece que estos nervios sean únicamente los que se dan en el animal perfecto a causa de su superioridad. De lo contrario, el animal de calor débil sería como el animal fuerte, o como el que se le parece, ya que no se puede prescindir de la existencia de estos nervios en él, sobre todo en el animal que no posee de las potencias del sentido más que esta potencia, como la esponja marina y otros. Y por eso vemos a muchos de los animales, cuyos miembros no tienen muchos órganos que, si se separan, quedan moviéndose algún tiempo, y las partes cortadas de los mismos sienten. Al contrario de lo que ocurre en el animal que consta de miembros con muchos órganos. Sin embargo, basta para la existencia de muchos de estos animales únicamente la existencia del corazón y del cerebro, o algo que equivalga al papel de ambos. ${ }^{17}$

Pasajes como el anterior no pueden leerse al margen de lo que Averroes describe en su Kitāb al-Kulliyyāt, cuyo libro primero está dedicado a la anatomía de los miembros. Averroes explica que las partes del cuerpo humano son de dos clases: por una parte, los órganos de partes similares (aquellos en los que la parte y el todo son una misma cosa); por otra, los miembros compuestos (aquellos cuyas partes no son semejantes unas de otras). Órganos simples son los huesos, los nervios, los tendones, las venas, los ligamentos, la carne, la grasa, la piel, la flema, la bilis negra, la bilis amarilla y el espíritu, es decir, el vapor que se percibe en el corazón y en el cerebro. Los órganos compuestos son las demás partes del cuerpo como, por ejemplo, la mano que es un compuesto de nervios y tendones. ${ }^{18}$ Los órganos simples o de partes similares tienen una composición homogénea y, a mi parecer, son lo que en terminología moderna podríamos denominar 'tejido estructural'. De éstas, la que más nos interesa son los nervios, aunque también es oportuno detenernos en los cuatro fluidos hipocráticos y en el denominado 'espíritu'. Los órganos compuestos están integrados por la mezcla de varios órganos simples

\footnotetext{
AVERROES: Epítome, 69.

AVERROES: Epítome, 71

Cf. AverRoes: Kulliyyāt, I.
} 
y, por tanto, en realidad esto es lo que más se acerca a lo que hoy en día denominamos propiamente 'órgano' (en Averroes abarca equívocamente las extremidades como la mano, pero también el hígado o, como veremos, el corazón, que para nosotros son propiamente órganos).

Ahora bien, los cuatro humores se consideran - también equívocamente, si pensamos en la medicina actual - órganos simples. ${ }^{19}$ Entre éstos, vuelve a incluirse uno que se menciona desde las tradiciones hipocrática y aristotélica y que no se sabe a ciencia cierta qué es, a saber, la bilis negra. ${ }^{20}$ Pero, además, se encuentran los 'espíritus': "Entre los órganos simples están la piel, las uñas y el pelo, como es evidente. También se hallan entre ellos los dos espíritus, el que se aprecia en el corazón y el que se aprecia en la cabeza. En el hígado no se observa ningún espíritu". Este pasaje salta a la vista: evidentemente Averroes se está refiriendo al espíritu ( $r \bar{u} h)$ en un sentido naturalista. El 'espíritu' no es algo inmaterial sino que, al parecer, se trata de un principio material, un vapor muy sutil, que resulta determinante para transmitir la temperatura del corazón y de la cabeza, concretamente del cerebro. Éste enfría; aquél calienta. Escribe Averroes: "El cerebro es frío porque las partes más abundantes en él son la médula y los nervios. La médula que hay en él es, por naturaleza, fría y húmeda, al contrario de la médula que hay en los huesos, y la prueba de que la médula del cerebro es más fría que la de los huesos es que no hay en ella parte grasienta y cuando se cuece se endure$\mathrm{ce}^{\prime 2}{ }^{22}$

Nótese cómo Averroes mantiene el principio aristotélico según el cual el cerebro enfría. El corazón, siguiendo también a Aristóteles, calienta. En esto Averroes sigue al Estagirita al pie de la letra. En donde existirá una diferencia radical es en la importancia que dará Averroes al cerebro en el conocimiento. ¿Qué importancia tienen estos referentes? Reconstruiré el argumento averroísta con el objeto de clarificar qué relevancia tienen estas consideraciones anatómicas para explicar la aísthesis. Mostraré, primero, la relación que existe entre corazón y calor interno. Escribe Averroes: "(..) en el corazón hay un cuerpo vaporoso [el espíritu], caliente hasta el límite, que nace de él y llega por los conductos llamados arterias a todos los órganos, según se dijo, e igualmente se cree que sucede con el cerebro". ${ }^{23}$ Gracias a la distribución de ese cuerpo vaporoso por todo el organismo, pueden realizar todos los órganos la totalidad de sus funciones. De modo que, siguiendo a Aristóteles, Averroes establece la superioridad del corazón sobre el resto de los órganos ("él se basta a sí mismo en sus acciones, mientras que los demás lo necesitan a él para las suyas"). ${ }^{24}$ El corazón es un órgano compuesto y, según Averroes, "(..) los órganos simples no existen más que por causa de los compuestos y los

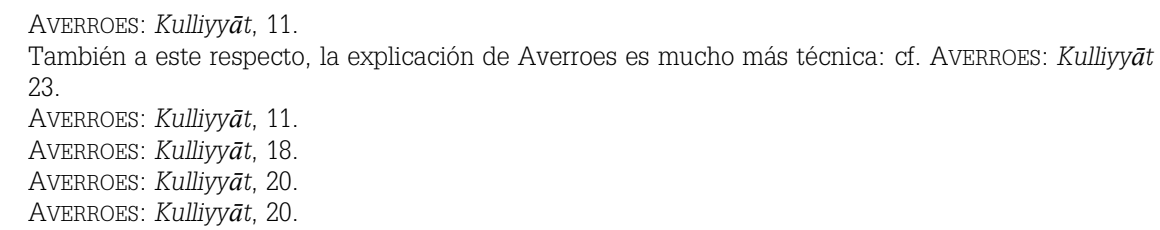


compuestos por causa de este calor enviado del corazón solamente o del cerebro y del corazón, si bien no vamos a probar aquí de qué modo este calor es el que ocupa el lugar de la forma y su totalidad constituye las funciones activas y pasivas propias de cada órgano". ${ }^{25}$ Averroes asume que las potencias existentes en el ser humano son tres: natural, animal e intelectual. Me detendré solamente en las potencias animales, es decir, en la aísthēsis. Precisamente, ahí es en donde Averroes establece una relación entre el corazón y la aísthēsis: "[llamo potencias animales] a la del pulso, que reside en el corazón, y a la impulsiva, que inclina hacia una cosa o hace huir de ella". ${ }^{26}$

Hasta aquí observamos cómo el corazón es indispensable para mantener el calor que hace posible que todos los órganos lleven a cabo sus funciones. Sin embargo el corazón no es el único órgano que interviene. Lo hace también el cerebro. De modo, pues, que existe una relación entre corazón y cérebro. ${ }^{27} \mathrm{Al}$ fondo de esta concepción se encuentra un viejo principio médico sustentado en los opuestos: frío contra caliente o, como se conocerá en el mundo latino y en el Renacimiento: cerebrum contra cor. Hay en la explicación averroísta dos aspectos destacables: primero, supuestamente el cerebro está subordinado al corazón y sin embargo necesita de él para que las sensaciones sean correctas. Esto es así por el segundo aspecto destacable, a saber, que en realidad los cinco sentidos son mucho más dependientes del cerebro que del corazón y Averroes lo sabe. De modo que, a mi parecer, se está percatando de la centralidad del cerebro para las funciones motoras, sensitivas (oído, vista, olfato, gusto) y, como dejaremos esbozado hacia el final, de las cognoscitivas. Sin embargo, Averroes intenta permanecer fiel al aristotelismo y el corazón sigue siendo un agente central. Menciono a continuación el pasaje en el que vincula los cuatro sentidos con el cerebro. Hago notar que

\footnotetext{
AVERROES: Kulliyyāt, 20.

AVERROES: Kulliyyāt, 21.

"Decimos que la anatomía muestra que muchas grandes arterias llegan al cerebro procedentes del corazón, y esto lo admiten todos los anatomistas, entre ellos Galeno. De aquí se deduce como primera prueba que el cerebro necesita del corazón para realizar esta función [la sensación]. Pero si el corazón solamente transmitiera al cerebro con el calor la facultad nutritiva con la que alimentarse, el corazón estaría, necesariamente, al servicio del cerebro porque la nutrición y la potencia nutritiva se encuentran en el animal por causa de los sentidos y de la facultad sensitiva. Y si lo que comunica con este calor es el uso de los cinco sentidos, la facultad sensitiva principal y primera estaría en el corazón. Esta facultad es la que se conoce como "sentido común» y su existencia se prueba en el Libro sobre el alma. Galeno, como hemos dicho, opina que esta facultad común reside en el cerebro, mientras que Aristóteles cree que está en el corazón (..) es evidente que el calor con el que funcionan los sentidos es el calor del corazón y la facultad que rige el sentido común está en él. El cerebro es un servidor de esta facultad y su dominio sobre los demás órganos no es un dominio absoluto. (..) como ya se ha declarado, el cerebro está subordinado al corazón en los actos de la facultad sensitiva, al modo de jefe del ejército que sirve al rey cumpliendo sus deseos, mientras que el rey es el que da órdenes y él las ejecuta y actúa según tales órdenes. Y ya conviene que veamos de qué modo sirve el cerebro al corazón, igual que analizamos cómo sirve el hígado al corazón, que es suministrándole alimentos. (..) Como el corazón es extraordinariamente caliente, el cerebro está dispuesto para equilibrar el calor [del corazón] a fin de que las sensaciones sean correctas. Esa frialdad [que atempera el calor excesivo] no se pudo poner en el corazón porque disminuirían mucho las operaciones nutritivas. La naturaleza pretendió colocar estas dos acciones en el animal superior, por lo que unió el corazón al cerebro" (AVERROES: Kulliyyāt, 29 y 30).
} 
el tacto está fuera de la lista. Éste merece atención aparte porque Averroes se ha dado cuenta que, para explicar su funcionamiento, hace falta recurrir a los nervios. Trataré de mostrar que Averroes se dará cuenta de que, en realidad, todos los demás sentidos también hacen necesaria la explicación sobre los nervios. Revisemos el siguiente pasaje:

Decimos que los sentidos son cuatro: el oído, la vista, el olfato y el gusto. Es evidente que el cerebro ha sido hecho para ellos, que residen en él, especialmente el oído, la vista y el olfato. Del mismo modo, es evidente que cada sentido tiene su propio instrumento: el de la vista es el ojo, el del oído es la oreja, el del olfato la nariz y el del gusto la lengua. Más tarde determinaremos las utilidades de cada una de las partes de estos instrumentos. En cuanto al instrumento propio [del sentido] del tacto hay muchas dudas. Galeno opina que el nervio procedente del cerebro podría ser el instrumento de este sentido y que es el que comunica a los demás órganos de esta facultad, en tanto Aristóteles piensa que [el instrumento del tacto] es la carne, divergencia que proviene de sus propias opiniones sobre el cerebro. Galeno cree que en él residen los cinco sentidos y al mismo tiempo opina que es órgano rector de esta operación, es decir, que la realiza por sí mismo sin necesidad de cualquier otro órgano. Aristóteles, por el contrario, opina que su superioridad es sólo parcial y que está subordinado en esta acción al corazón, tanto si son cinco como si son cuatro los sentidos que residen en él. ${ }^{28}$

Averroes admite varias ideas galénicas: que el nervio procedente del cerebro es el instrumento del tacto; que los cinco sentidos residen en el cerebro. No obstante, comparte con Aristóteles que de alguna manera el cerebro está subordinado a la acción del corazón o, al menos, ambos interactúan para que pueda darse la sensación. Pero hay todavía más: Averroes explica que los sentidos residen en el cerebro, que existe un instrumento corporal específico para que se dé su funcionamiento. Sin embargo, ello no basta para explicar la aísthēsis. He aquí la novedad frente a Aristóteles. Influido por Galeno y por Avicena, Averroes entiende que la sensación no radica directamente en el cerebro ni tampoco en los sentidos, sino en las terminales nerviosas que se unen a él. Me parece que esto es definitivo para completar la teoría de la sensación que hay tanto en el De anima como en Acerca del sentido y lo sensible. Aristóteles se ocupa de los medios externos al órgano que posibilitan la sensación, por ejemplo, lo transparente y lo diáfano son un medio para la vista. Averroes concibe, además, que existe una 'mediación' entre el cerebro y el órgano de cada sentido. Esto se observa de manera más clara en el caso del tacto: el órgano o instrumento que hace posible el tacto es, en efecto, la carne; sin embargo, la carne no sentiría si no hubiese terminales nerviosas que se conectan directamente al cerebro: "En los animales superiores hay nervios que regulan la complexión de la carne y como su sustancia es similar a la del cerebro, su utilidad es del mismo tipo que la de éste". ${ }^{29}$ Si los peripatéticos hubiesen reconocido la importancia de los nervios en la experiencia sensorial, hubiesen evitado

AvERROES: Kulliyyāt, 29. El subrayado es mío.

AvERROES: Kulliyyāt, 30; cf. también Commentarium Magnun II, 116, p. 312. 
la tendencia a entender la sensación solamente desde los órganos propios de cada sentido. Por ejemplo, Averroes explica, como Aristóteles, que el ojo es instrumento de la vista. Su descripción es mucho más precisa que la aristotélica, ya que conoce varias partes del ojo. Y nos dice: "La retina tiene como primera utilidad transportar el espíritu visual por medio del nervio que hay en ella. Este nervio es el calor innato, cuya complexión se ha equilibrado en el cerebro y en los dos nervios que penetran los ojos. Además, nutre al humor vítreo por infiltración y le aporta calor natural por medio de sus arterias". ${ }^{30}$

Al explicar el olfato, Averroes presta menor atención a los nervios y explica más la aspiración del aire. ${ }^{31}$ Sin embargo, cuando explica el oído, dice: "El instrumento del oído, evidentemente, son las dos orejas. El primer instrumento es el nervio que llega allí cubriendo su orificio". Sin duda, la concepción averroísta de los nervios es bastante completa para su tiempo. Nos explica que: "Las cabezas de estos cuerpos [los nervios] aparecen unidas o con el cerebro o con la médula, por lo que se piensa que se originan de ambos. La parte superior de la médula aparece unida con la parte superior del cerebro, cuyas membranas la envuelven, y se extiende hasta llegar al hueso llamado cóccix, por lo que se cree que también ella se origina en el cerebro". ${ }^{33}$

En el libro primero de su Kitāb al-Kulliyyāt describe Averroes cada una de las terminales nerviosas del cuerpo humano, ${ }^{34}$ con especial énfasis a lo que podríamos denominar ya 'sistema nervioso'. Da un paso adelante del aristotelismo: la sensación no se explica solamente por la acción del órgano destinado a cada sentido; se necesita, además, del sistema nervioso. Éste es tan relevante que si hay en él algún tipo de atrofia, no existe la sensación. El cuerpo humano tiene terminales nerviosas por todos lados y éstas se conectan principalmente con el cerebro y con la médula. Y a pesar de estas diferencias que suponen un avance en la anatomía, Averroes es fiel al Estagirita. Menciono un punto muy específico en donde se manifiesta este acuerdo: Averroes comparte que los órganos están dispuestos de determinada manera porque la potencia así lo exige, cuando, en efecto, podríamos pensar a la inversa, a saber, que la función existe porque el órgano ha sido dispuesto para ello. Escribe Averroes: “(..) Es evidente que los órganos no existen más que por causa de estas potencias y éstas por causa de sus acciones. Por lo tanto, no hay ningún órgano en el cuerpo que no tenga una función, manifestada de manera activa o pasiva". ${ }^{35}$

Una de las funciones más importantes del alma es la sensación y ésta se explica a través de la interacción del corazón, el cerebro, el sistema nervioso y los órganos de cada sentido. Lo que Averroes aporta es la descripción del alma como un conjunto de funciones entre las que destaca la explicación más puntual de la

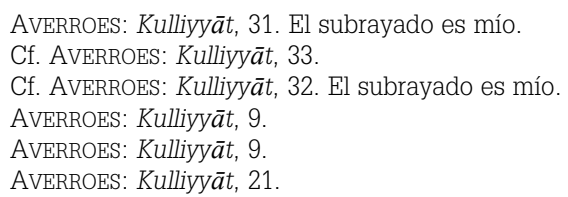


aísthesis. Y va todavía más allá: la detección de los sentidos internos en lugares específicos del cerebro es referencia obligada si se quiere comprender su doctrina del intelecto. Averroes distingue seis clases de intelecto: intelecto pasivo, intelecto especulativo o teórico, intelecto in habitu, intelecto adquirido, intelecto material, intelecto agente. Es el intelecto pasivo, nous pathetikós en Aristóteles, el que comprende el sentido común, la cogitativa, la memoria y la imaginación, el que es generable y corruptible y está situado en el cerebro. Tal parece que, como lo ve Averroes, en el De anima toda operación humana, salvo el pensamiento, es explicable desde los procesos fisiológicos. Esto lo ha dejado claro desde la introducción del Epítome:

Se declaró también con ello cómo este calor conveniente para la información y para la creación no es suficiente para la donación de la figura y de la forma externa, si no hay ahí una facultad informada del género del alma nutritiva. Y que esta facultad nutritiva y sensitiva es engendrada en el animal por otra semejante, y que el agente último de la misma está separado y se llama entendimiento. Al ser el agente próximo la facultad anímica que está en el cuerpo, estos miembros orgánicos no se encuentran más que animados. Pues si no estuviesen animados, les correspondería la existencia analógicamente, de la misma manera que se llama mano a la mano del muerto y a la mano del vivo. ${ }^{36}$

En el Gran Comentario, Averroes distingue entre sensación e intelección y explica que, aunque parece que el intelecto tiene mucho en común, finalmente hay en el noūs algo separable. ${ }^{37}$ No obstante, esta afirmación conlleva otro problema: ¿Radica el noūs en algún órgano? Si Averroes respondiera afirmativamente, sería poco aristotélico. En efecto, no existe ningún pasaje en el que Aristóteles dé importancia alguna al cerebro en la operación gnoseológica. En cambio, Averroes va más allá. Gracias a los avances de los árabes en la anatomía cerebral, se percató de que el cerebro sí interviene en nuestro conocimiento. Ello no quiere decir que resolviera los problemas implícitos en la teoría del conocimiento desde explicaciones meramente fisiológicas. No obstante, sí nos permite descubrir que el trayecto que lleva a la doctrina del intelecto es prácticamente fisicalista.

\section{Bibliografía}

M. Alonso: Teología de Averroes. Estudios y documentos. CSIC: Madrid/Granada, 1947.

ARistóteles: Acerca del alma. Traducción de T. Calvo, Gredos, Madrid, 1978.

ARISTÓteles: Reproducción de los animales. Traducción de E. SÁnCHEZ, Madrid: Gredos, 1994.

AverRoes: Epitome De anima. Edición S. GÓmez Nogales, Consejo Superior de Investigaciones Científicas, Instituto Hispano-Árabe de Cultura, Madrid, 1985 (versión castellana en La psicología de Averroes. Madrid: Universidad Nacional de Educación a Distancia, 1987).

AvERROES: Epítome, 6. El subrayado es mío.

Cf. Averroes: Commentarium Magnum III, 3, p. 382. 
AverRoes: Middle Commentary on Aristotle's De anima. Edición crítica del texto árabe a cargo de A. L. IVRY. Brigham Young University Press, Provo, Utah, 2002.

AverRoes: Commentarium magnum in Aristotelis De anima libros, The Mediaeval Academy of America, Cambridge: Massachussets, 1953.

AvERROES: Libro de las generalidades de la Medicina (Kitāb al-Kulliyyāt fīl-tibb) traducción de M. VÁzQUEZ DE BENito y C. ÁlVAReZ Morales. Madrid: Trotta, 2003.

A. IvRY: "Averroes' Three Commentaries on De Anima", en Averroes and the Aristotelian Tradition, G. ENDRESS y J. A. AERTSEN (eds.). Leiden: E. J. Brill, 1999, p. 199-216. 